\title{
Comparative Evaluation of Clonidine as an Adjunct to Ropivacaine for Caudal Block Anaesthesia in Children Undergoing Sub-Umbilical Surgeries
}

\author{
Priyash Verma1 ${ }^{1}$ Ravishankar R.B. ${ }^{2}$ \\ 1,2 Department of Anaesthesia, JJM Medical College, Davanagere, Karnataka, India.
}

\section{ABSTRACT}

\section{BACKGROUND}

Studies suggest that clonidine can improve the duration of analgesia, quality of pain control when used with ropivacaine for caudal blocks in children. This study was designed to understand the effects of caudally administered ropivacaine $0.25 \%$ $(1 \mathrm{ml} / \mathrm{kg})$ alone and ropivacaine $0.25 \%(1 \mathrm{ml} / \mathrm{kg})$ with clonidine $2 \mathrm{mcg} / \mathrm{kg}$, in children between 2- 10 years.

\section{METHODS}

Sixty children posted for various sub-umbilical surgical procedures were included after written informed consent and ethics committee approval. Children were randomly divided into 2 groups of 30 each: Group R -ropivacaine $0.25 \% 1 \mathrm{ml} / \mathrm{kg}$ into caudal epidural space and Group RC-ropivacaine $0.25 \% 1 \mathrm{ml} / \mathrm{kg}$ and clonidine $2 \mathrm{mcg} / \mathrm{kg}$ into caudal epidural space.

\section{RESULTS}

The mean age of patients was similar with no statistical difference ( 4.83 vs $5.36, \mathrm{P}=$ 0.3353). The duration of anaesthesia was significantly longer in the RC group (544.83 minutes vs 268.00 minutes, $\mathrm{P}<0.0001$ ). The effect size was very high (Cohen $d=23.86$ ). The pain score was comparable up to 1 hour for the two groups. But 2 hours later, the pain scores were significantly lower for the ropivacaine and clonidine groups. The effect on motor blockade was similar in both groups with no motor blockade at 4 hours follow up. 5 cases of urinary retention were seen in the study with no statistically significant difference in terms of complication rate between the two groups. No case of hypotension or bradycardia was seen. There was a significant difference between the two groups in terms of cardiovascular parameters (HR, SBP, DBP) after administration of drugs.

\section{CONCLUSIONS}

The addition of clonidine to ropivacaine for caudal blocks in children was associated with better quality of pain control and a longer duration of analgesia without any additional motor blockade. There was no significant difference seen in terms of complication.

\section{KEY WORDS}

Analgesia Duration, Caudal Analgesia, Clonidine, Pain Control, Ropivacaine.
Corresponding Author: Dr. Priyash Verma, Department of Anaesthesia, JJM Medical College, Davanagere, Karnataka, India. E-mail:drpsv90@gmail.com

\section{DOI: $10.14260 / \mathrm{jemds} / 2021 / 765$}

How to Cite This Article:

Verma P, Ravishankar RB. Comparative evaluation of clonidine as an adjunct to ropivacaine for caudal block anaesthesia in children undergoing sub-umbilical surgeries. J Evolution Med Dent Sci 2021;10(44):3785-3790, 10.14260/jemds/2021/765

Submission 29-08-2021, Peer Review 19-11-2021, Acceptance 25-11-2021, Published 30-11-2021.

Copyright (c) 2021 Priyash Verma et al. This is an open access article distributed under Creative Commons Attribution License [Attribution 4.0 International (CC BY 4.0)] 


\section{BACKGROUND}

Caudal anaesthesia was first described by Fernand Cathelin and Jean Athanase Sicard in the year 1895. It was an extension of the lumbar approach to epidural block which existed for more than a decade. The evolution of caudal blocks for paediatric anaesthesia has grown since its inception in 1993.1 ${ }^{1}$ It has been shown to confer high degrees of analgesia both intraoperatively as well as postoperatively in sub-umbilical surgeries in children. ${ }^{2}$ It is a simple technique to perform and is the cornerstone in paediatric regional anaesthesia.

Ropivacaine has been an agent of choice for regional anaesthesia in adults and older children. ${ }^{3}$ It has been shown to have documented safety even in the younger age group for caudal epidural analgesia.4,5,6 Ropivacaine is a safer drug of choice for regional blocks and day-care surgeries due to the lower incidence of cardiovascular side effects and neurotoxicity along with the lower incidence of motor blockade compared to bupivacaine. ${ }^{3,7}$ Ropivacaine at concentrations of $0.5 \%(0.75 \mathrm{ml} / \mathrm{kg})$ can cause a prolonged duration of analgesia as compared to $0.25 \%$ ropivacaine. However, these levels are shown to be associated with higher plasma levels and often related to early signs of toxicity in children coupled with an increased motor blockade. ${ }^{8}$

Clonidine is a combined alpha-1and alpha- 2 agonist, with prevalent alpha- 2 action. It is primarily an antihypertensive agent but of late, its sedative, anxiolytic and analgesic properties are being utilized in various applications. One such application is co-administration along with a local anaesthetic agent to improve the quality of the analgesia and the duration of analgesia. Peripheral vasodilation leading to a fall in arterial blood pressure, heart rate as well as cardiac output is frequently seen with clonidine.

Multiple studies have been performed in this domain, albeit on smaller sample sizes. Studies by Laha, ${ }^{9}$ Manickam, ${ }^{10}$ Chaudhary ${ }^{11}$ and Bajwa et al. ${ }^{12}$ have shown that clonidine can improve the duration of analgesia and quality of pain control. However, similar studies on larger sample sizes were needed to further validate the results and add to the pool of existing literature in this aspect.

This study was designed to analyse the effects of $0.25 \%$ ropivacaine $(1 \mathrm{ml} / \mathrm{kg})$ alone compared to $0.25 \%$ ropivacaine $(1 \mathrm{ml} / \mathrm{kg}$ ) combined with clonidine $(2 \mathrm{mcg} / \mathrm{kg})$, for elective sub-umbilical surgeries in children between 2-10 years of age, in terms of duration of sensory and motor blockade, quality of analgesia and adverse event profile.

\section{METHODS}

This study was conducted at Chigateri General Hospital, Child Health Institute and Bapuji Hospital attached to J.J.M Medical College, Davangere between October 2015 and October 2017. Our sample size was calculated based on pilot study data. We used a confidence level (1- $\alpha$ ) of $90 \%$ and power of the study (1- $\beta$ ) $80 \%$. We recruited 60 children of either gender, posted for various sub-umbilical surgical procedures such as circumcision, appendicectomy, orchidopexy, inguinal herniotomy, perineal and urological surgeries. This study was conducted after approval from the Institutional Ethics and
Standards committee. We obtained informed consent from the parents before recruiting the children in our study.

We included children undergoing elective sub-umbilical surgeries, ages between 2 and 10 years of either gender and ASA grade 1 or 2. Children with known allergies to any drugs, especially local anaesthetics, spinal or meningeal abnormalities, local infection around the caudal region, history or investigations suggestive of coagulopathy, ASA grade III \& IV disease, or those posted for emergency surgeries were excluded from our study.

The patients were evaluated a day prior to the operation including a detailed general physical and systemic examination including that of the airway and spine. Baseline vitals were recorded. Findings from routine investigations such as full blood count, routine urine test, coagulation profile, serology, and chest x-ray, if indicated were noted. We consented to the parents/guardian for the anaesthetic, and a patient information sheet was provided. Conventional fasting guidelines were set i.e., solid foods stopped 6 hours, milk 4 hours and water 2 hours before the procedure.

On arrival into the operating room, usual monitors such as pulse oximeter, 3-lead ECG leads and NIBP cuff was connected, and baseline vitals were noted throughout the caudal block procedure and operation.

The children were randomly divided into 2 groups with 30 in each, using sealed envelopes. Children in Group R were given ropivacaine $0.25 \% 1 \mathrm{ml} / \mathrm{kg}$ into caudal epidural space, and those in Group RC were given ropivacaine $0.25 \% 1$ $\mathrm{ml} / \mathrm{kg}$ and clonidine $2 \mathrm{mcg} / \mathrm{kg}$ into caudal epidural space.

After gas induction with a volatile agent in oxygen using a Jackson-Rees circuit, 22G IV cannula was secured. Intravenous glycopyrrolate $0.01 \mathrm{mg} / \mathrm{kg}$ followed by intravenous fentanyl $2 \mu \mathrm{g} / \mathrm{kg}$ was given. An I.V infusion of ringer lactate was started for maintenance, and fluid was administered as per calculated requirements.

The child was kept in a semi-flexed lateral position. With gentle bag-mask ventilation, vitals were continuously monitored. Using strict asepsis, the sacral hiatus was identified sliding the thumb over the spine from the spinous process towards the coccyx. With the sacral hiatus successfully identified, a 22G hypodermic needle was inserted at a 45-degree angle, with the bevel facing anteriorly, till a 'pop' or loss of resistance was appreciated indicating piercing of the sacrococcygeal membrane. Using a 'whoosh test', the accurate placement of the needle was confirmed. After verifying negative aspiration to CSF and blood, the drug was injected into the caudal space. After injection, the needle was removed, the site of injection was wiped with a betadine swab and the child was placed in the supine position. Anaesthesia was then maintained on oxygen, nitrous oxide, and inhalational agent with the patient kept spontaneously ventilated throughout the surgery.

At the start of skin closure, anaesthetic agents were discontinued and $100 \%$ oxygen was administered through a face mask. Once the child was awake and the vitals were stable, the child was shifted and placed in a lateral position in the recovery room. On arrival to the recovery room, the child was monitored for one hour with pulse oximetry and NIBP every 15 minutes. After that child was shifted to the ward and monitored. 


\section{Parameters Studied}

The haemodynamic parameters studied were the child's heart rate, blood pressure and respiratory rate after administration of caudal block at $0,5,10,15,30$ minutes and there on for every 15 minutes till the end of procedure.

In addition, the time of caudal injection, duration of anaesthesia, duration of sensory and motor blockade and the time of first dose of rescue analgesia postoperatively were also recorded.

Motor block was assessed on the awakening by using a modified Bromage scale, that consisted of 4 points: $0=$ full motor strength (flexion of knees and feet), 1 = flexion of knees, 2 = little movement of feet only, 3 = no movement of knees or feet. However, younger children who could not move their legs on command were stimulated by tapping on the legs and feet.

Pain scores were assessed post-operatively after recovery by an anaesthesiologist and then by a single person at $1,2,4$, 8 and $12 \mathrm{~h}$ with a 5 -point observer pain score (OPS): $1=$ asleep or awake and laughing, $2=$ awake, but no pain, $3=$ mild pain (irritable/restless), $4=$ moderate pain (crying, grimacing restless but consolable) and $5=$ severe pain (crying/screaming/inconsolable). The duration of absolute analgesia was defined as the time from caudal injection until the pain score was $>2$. Rescue analgesia was given for a pain score $=/>4$. Post-operatively analgesic rescue dose was given based on the visual and verbal analogue score with ibuprofen and paracetamol syrup.

The children were monitored for any intra or postoperative complications. We defined hypotension as a decrease in mean arterial pressure of greater than $30 \%$ of the baseline value., intending to treat with IV fluid bolus and IV ephedrine $0.1-0.3 \mathrm{mg} / \mathrm{kg}$ as needed. Any episodes of nausea and vomiting were noted.

\section{Statistical Analysis}

The data was compiled and analysed using MS Excel (R) office 365, GraphPad prism 8.4.2 and SPSS version 25. Descriptive statistics were presented in the form of tables and figures. Proportions/percentages were used for the categorical variables and mean \& standard deviation were used for continuous data. Fisher Exact test/chi-square test was used for the comparison of proportions (Categorical variables). Continuous variables were analysed using the student T-test for independent group/Unpaired data, assuming a normal distribution. The effect size for independent sample T-tests with significant findings was assessed via the Cohen's d, glasses' delta value and Hedges' g value using standard online calculators. Multiple group analysis for paired follow up data was done by one-way ANOVA test. A P-value of $<0.05$ was considered significant.

\section{RESULTS}

\section{Baseline Parameters}

The mean age of patients across both the groups was similar with no statistical difference (4.83 vs $5.36, \mathrm{P}=0.3353$ ). A comparison of the other baseline parameters showed that there was no significant difference between the two groups in terms of gender, body weight, surgical procedure type and duration of surgery (Table 1).

\section{Clinical Parameters}

A summary of the comparative evaluation of the clinical parameters after administering the drugs has been shown in Table 2. It was seen using repeat measure ANOVA that heart rate, systolic blood pressure (SBP) and diastolic blood pressure (DBP) had fallen significantly $(\mathrm{P}<0.0001)$ during the follow up for both the groups. The mean heart rate was comparable for the two groups up to 15 mins, after which it became significantly lower for the ropivacaine with clonidine group. The Cohen's d statistic suggestive of effect size showed medium effect size ( $d=0.5-0.8)$ at 30 mins follow up and large effect size for time points 45 minutes to 1 hour $(\mathrm{d}=0.8$ and above). The SBP was comparable at the baseline but showed a significantly higher drop in the ropivacaine with clonidine group from 0 minute onwards $(\mathrm{P}=0.0226)$. The SBP levels were consistently lower in the ropivacaine and clonidine groups. The effect size was medium initially $(d=0.60$ at 0 minutes and $\mathrm{d}=0.54$ at 15 minutes) and increased as the follow up increased $(\mathrm{d}=0.91$ at 45 minutes and $d=1.09$ at 1 hour). The DBP was comparable at the baseline but showed a significantly higher drop in the ropivacaine with clonidine group from 0 minutes onwards $(P=0.0255)$. The SBP levels were consistently significantly lower in the ropivacaine and clonidine groups. The effect size was medium initially $(\mathrm{d}=$ 0.54 at 0 minutes) and increased as the follow up increased $(d=0.84$ at 5 minutes and $d=1.74$ at 1 hour $)$.

\section{Outcome Parameters}

The main outcome parameters assessed were the duration of anaesthesia, pain, and motor blockade. The duration of anaesthesia was significantly higher in the ropivacaine and clonidine group (544.83 minutes vs 268.00 minutes, $\mathrm{P}<$ 0.0001 ). The effect size was very high (Cohen $d=23.86$ ). The pain score was comparable up to 1 hour for the two groups. But 2 hours onwards, the pain scores were significantly lower for the ropivacaine and clonidine groups (Figure 1). The effect size was large between 2 and 8 hours $(\mathrm{d}=1.72,3.26$, and 2.94). The effect on motor blockade was similar between the two groups with $n$ significant difference. Both the groups had no motor blockade at 4 hours follow up. A summary of the comparative evaluation of outcome parameters has been shown in Table 3.

\section{Complications}

5 children developed postoperative urinary retention with three cases in the ropivacaine and clonidine group and 2 cases in the ropivacaine group, with no statistically significant difference in terms of complication rate between the two groups. No case of hypotension, bradycardia or postoperative nausea and vomiting was seen in either group. 


\begin{tabular}{|c|c|c|c|}
\hline Parameter & RC Group & R Group & P-Value \\
\hline \multicolumn{4}{|c|}{ Age (in years) } \\
\hline Mean \pm SD & $4.83 \pm 2.00$ & $5.36 \pm 2.22$ & 0.3353 \\
\hline \multicolumn{4}{|c|}{ Gender N (\%) } \\
\hline Male & $29(96.67)$ & 29 (96.67) & $>0.999$ \\
\hline Females & $1(3.33)$ & $1(3.33)$ & \\
\hline \multicolumn{4}{|c|}{ Bodyweight (in kgs) } \\
\hline Mean \pm SD & $12.83 \pm 3.23$ & $14.20 \pm 3.33$ & 0.1112 \\
\hline \multicolumn{4}{|c|}{ Surgical procedure N (\%) } \\
\hline Herniotomy & $18(60)$ & $15(50)$ & 0.4401 \\
\hline Hypospadias Repair & $2(6.67)$ & $4(13.33)$ & 0.3939 \\
\hline Orchidopexy & $4(13.33)$ & $4(13.33)$ & $>0.999$ \\
\hline Circumcision & $6(20)$ & $6(20)$ & $>0.999$ \\
\hline Open Appendicectomy & $0(0)$ & $1(3.3)$ & 0.3198 \\
\hline \multicolumn{4}{|c|}{ Duration of surgery (in mins) N (\%) } \\
\hline$<30$ & $6(20)$ & $6(20)$ & $>0.999$ \\
\hline $30-50$ & $20(66.67)$ & $19(63.33)$ & 0.7880 \\
\hline$>50$ & $4(13.33)$ & $5(16.67)$ & 0.7194 \\
\hline
\end{tabular}

\begin{tabular}{|c|c|c|c|c|c|c|}
\hline Parameter & $\begin{array}{l}\text { RC group } \\
\text { (Mean } \pm \\
\text { SD) }\end{array}$ & $\begin{array}{l}\text { R group } \\
\text { (Mean } \pm \\
\text { SD) }\end{array}$ & $\begin{array}{c}P \\
\text { Value }\end{array}$ & $\begin{array}{c}\text { Cohen's } \\
\text { d }\end{array}$ & $\begin{array}{c}\text { Hedges' } \\
\text { g }\end{array}$ & $\begin{array}{c}\text { Glasses' } \\
\text { delta }\end{array}$ \\
\hline \multicolumn{7}{|c|}{ Heart rate (per min) } \\
\hline Baseline & $105.20 \pm 4.25$ & $103.83 \pm 6.41$ & 0.3333 & - & - & - \\
\hline 0 mins & $100.33 \pm 4.10$ & $100.03 \pm 6.59$ & 0.8331 & - & - & - \\
\hline 5 mins & $96.0 \pm 4.16$ & $96.10 \pm 6.03$ & 0.9407 & - & - & - \\
\hline 15 mins & $91.60 \pm 4.46$ & $93.23 \pm 5.40$ & 0.2075 & - & - & - \\
\hline 30 mins & $87.46 \pm 4.09$ & $90.60 \pm 5.82$ & 0.0188 & 0.62 & 0.62 & 0.76 \\
\hline 45 mins & $85.06 \pm 2.91$ & $89.86 \pm 4.61$ & $<0.0001$ & 1.24 & 1.24 & 1.64 \\
\hline $1 \mathrm{hr}$ & $83.06 \pm 1.94$ & $88.43 \pm 4.93$ & $<0.0001$ & 1.43 & 1.43 & 2.76 \\
\hline \multicolumn{7}{|c|}{ Systolic blood pressure (in mm Hg) } \\
\hline Baseline & $88.60 \pm 1.49$ & $90.26 \pm 4.60$ & 0.0651 & - & - & - \\
\hline 0 mins & $85.73 \pm 2.81$ & $87.93 \pm 4.31$ & 0.0226 & 0.60 & 0.60 & 0.78 \\
\hline $5 \mathrm{mins}$ & $84.13 \pm 2.09$ & $85.53 \pm 3.81$ & 0.0829 & - & - & - \\
\hline 15 mins & $83.53 \pm 1.63$ & $85.06 \pm 3.62$ & 0.0391 & 0.54 & 0.54 & 0.93 \\
\hline 30 mins & $83.13 \pm 2.55$ & $84.73 \pm 3.68$ & 0.0551 & - & - & - \\
\hline 45 mins & $82.46 \pm 1.71$ & $85.06 \pm 3.62$ & 0.0008 & 0.91 & 0.91 & 1.52 \\
\hline $1 \mathrm{hr}$ & $81.86 \pm 2.02$ & $84.86 \pm 3.30$ & 0.0001 & 1.09 & 1.09 & 1.48 \\
\hline \multicolumn{7}{|c|}{ Diastolic blood pressure (in mm Hg) } \\
\hline Baseline & $51.93 \pm 4.25$ & $53.40 \pm 6.03$ & 0.2796 & - & - & - \\
\hline 0 mins & $47.73 \pm 3.88$ & $50.86 \pm 6.39$ & 0.0255 & 0.59 & 0.59 & 0.80 \\
\hline 5 mins & $45.20 \pm 2.49$ & $48.60 \pm 5.12$ & 0.0018 & 0.84 & 0.84 & 1.36 \\
\hline 15 mins & $43.60 \pm 2.06$ & $47.86 \pm 4.16$ & $<0.0001$ & 1.29 & 1.29 & 2.06 \\
\hline 30 mins & $43.33 \pm 2.24$ & $47.93 \pm 4.62$ & $<0.0001$ & 1.26 & 1.26 & 2.05 \\
\hline 45 mins & $43.00 \pm 3.00$ & $48.26 \pm 4.44$ & $<0.0001$ & 1.38 & 1.38 & 1.75 \\
\hline $1 \mathrm{hr}$ & $42.26 \pm 1.46$ & $47.63 \pm 4.07$ & $<0.0001$ & 1.74 & 1.74 & 3.65 \\
\hline
\end{tabular}

\begin{tabular}{|c|c|c|c|c|c|c|}
\hline Parameter & $\begin{array}{c}\text { RC group } \\
(\text { Mean } \pm \text { SD) }\end{array}$ & $\begin{array}{l}\text { R group } \\
\text { (Mean } \pm \\
\text { SD) }\end{array}$ & $\begin{array}{c}P \\
\text { Value }\end{array}$ & $\begin{array}{c}\text { Cohen's } \\
\text { d }\end{array}$ & $\begin{array}{c}\text { Hedges' } \\
\text { g }\end{array}$ & $\begin{array}{c}\text { Glasses } \\
\text { delta }\end{array}$ \\
\hline $\begin{array}{l}\text { Duration of } \\
\text { anaesthesia } \\
\text { (In minutes) }\end{array}$ & $544.83 \pm 12.83$ & $\begin{array}{c}268.00 \pm \\
10.22\end{array}$ & $<0.0001$ & 23.86 & 23.86 & 21.57 \\
\hline \multicolumn{7}{|c|}{ Pain related parameters } \\
\hline Immediate & $1.00 \pm 0.00$ & $1.00 \pm 0$ & $>0.999$ & - & - & - \\
\hline $1 \mathrm{hr}$ & $1.00 \pm 0.34$ & $1.13 \pm 0.34$ & 0.1441 & - & - & - \\
\hline $2 \mathrm{hr}$ & $1.40 \pm 0.49$ & $2.10 \pm 0.30$ & $<0.0001$ & 1.72 & 1.72 & 1.42 \\
\hline $3 \mathrm{hr}$ & $2.00 \pm 0.37$ & $2.16 \pm 0.37$ & 0.0994 & - & - & - \\
\hline $4 \mathrm{hr}$ & $2.00 \pm 0.37$ & $3.10 \pm 0.30$ & $<0.0001$ & 3.26 & 3.26 & 2.97 \\
\hline $8 \mathrm{hr}$ & $3.00 \pm 0.36$ & $4.06 \pm 0.36$ & $<0.0001$ & 2.94 & 2.94 & 2.94 \\
\hline $12 \mathrm{hr}$ & $4.33 \pm 0.47$ & $4.63 \pm 0.55$ & 0.0269 & 0.586 & 0.586 & 0.638 \\
\hline \multicolumn{7}{|c|}{ Motor Blockade } \\
\hline Immediate & $1.63 \pm 0.14$ & $1.50 \pm 0.50$ & 0.1756 & - & - & - \\
\hline $1 \mathrm{hr}$ & $1.66 \pm 0.47$ & $1.63 \pm 0.49$ & 0.8096 & - & - & - \\
\hline $2 \mathrm{hr}$ & $1.16 \pm 0.37$ & $1.10 \pm 0.30$ & 0.4930 & - & - & - \\
\hline $3 \mathrm{hr}$ & $0.76 \pm 0.43$ & $0.70 \pm 0.46$ & 0.6037 & - & - & - \\
\hline $4 \mathrm{hr}$ & 0 & 0 & - & - & - & - \\
\hline$T a b$ & 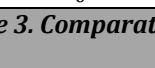 & $\begin{array}{l}\text { e Evalua } \\
\text { Follow }\end{array}$ & $\begin{array}{l}\text { of of Ou } \\
\text { Period }\end{array}$ & itcome & ames & $s$ in \\
\hline
\end{tabular}

\begin{tabular}{|c|c|c|c|c|c|}
\hline $\begin{array}{l}\text { Study } \\
\text { Name }\end{array}$ & Year & $\begin{array}{c}\text { Ropivacaine } \\
\text { Dose and } \\
\text { Strength }\end{array}$ & $\begin{array}{l}\text { Clonidine } \\
\text { Dose and } \\
\text { Strength }\end{array}$ & $\begin{array}{l}\text { Duration I } \\
\text { of } \\
\text { Analgesia } \\
\text { (Mins) }\end{array}$ & $\begin{array}{l}\text { Hypotension/ } \\
\text { Bradycardia/ } \\
\text { Motor } \\
\text { Impairment }\end{array}$ \\
\hline Present study & 2021 & $0.25 \%(1 \mathrm{ml} / \mathrm{kg})$ & $2 \mu \mathrm{g} / \mathrm{kg}$ & 544.83 & None \\
\hline Patagankar et al & 2021 & $0.25 \%, 0.5 \mathrm{ml} / \mathrm{kg}$ & $1 \mathrm{ug} / \mathrm{kg}$ & 600.25 & \\
\hline Shini et al & 2020 & $0.2 \%, 1 \mathrm{ml} / \mathrm{kg}$ & $2 \mu \mathrm{g} / \mathrm{Kg}$ & 380.71 & None \\
\hline Goodarzi et al & 2020 & $0.25 \%, 1 \mathrm{ml} / \mathrm{kg}$ & $1 \mathrm{ug} / \mathrm{kg}$ & 432 & None \\
\hline SJS Bajwa et al & 2010 & $0.25 \%, 1 \mathrm{ml} / \mathrm{kg}$ & $2 \mu \mathrm{g} / \mathrm{Kg}$ & - & None \\
\hline Gupta et al & 2014 & $0.2 \%, 1 \mathrm{ml} / \mathrm{kg}$ & $2 \mu \mathrm{g} / \mathrm{kg}$ & - & None \\
\hline Manickam et al & 2012 & $0.1 \%, 1 \mathrm{ml} / \mathrm{kg}$ & $1 \mu \mathrm{g} / \mathrm{Kg}$ & 590.25 & None \\
\hline Laha et al & 2012 & $0.2 \%, 1 \mathrm{ml} / \mathrm{kg}$ & $2 \mu \mathrm{g} / \mathrm{Kg}$ & 975 & None \\
\hline
\end{tabular}

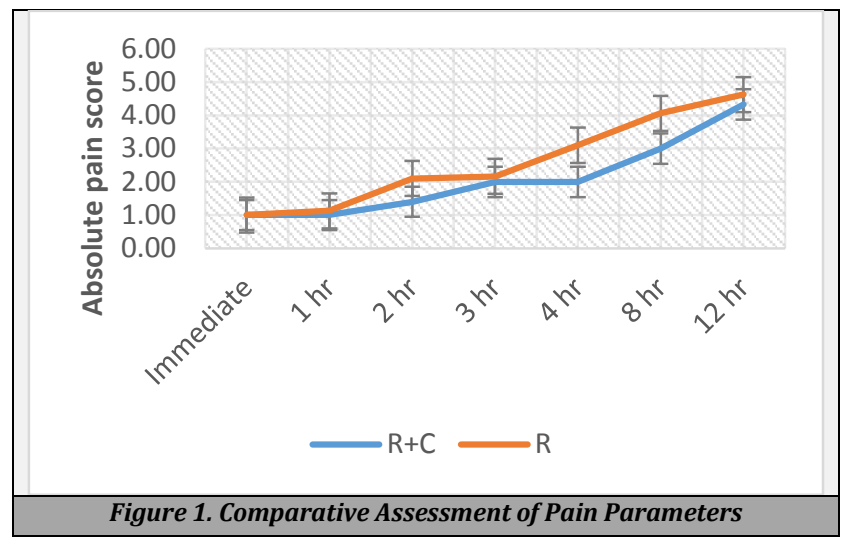

\section{DISCUSSION}

Ropivacaine is being increasingly used in the paediatric age group for caudal blocks because of its lower incidence of motor blockade and systemic toxicity. 4,5 The coadministration of clonidine with local anaesthetics has been shown to improve the quality of peripheral nerve block.13,14,15 A dose of $0.25 \% 1 \mathrm{ml} / \mathrm{kg}$ ropivacaine was selected for the study based on the findings of Ivani $G$ et al. ${ }^{16}$ This study highlighted that caudal block, with ropivacaine and clonidine, was associated with significantly longer duration of analgesia and better pain control in children compared to ropivacaine alone. The impact on the motor blockade was not significantly different suggesting that analgesia was prolonged without prolonging the motor blockade. However, this was seen to be associated with significantly lower cardiovascular parameters like heart rate, SBP and DBP especially between 15 minutes and 1 hour after the administration of the drugs. This can be attributable to the alpha- 2 adrenoceptor agonist action of clonidine. There was no added complication risk in patients receiving both the drugs for the caudal block. There was no case of hypotension or bradycardia in the study. A comparison of the findings of the major studies in this domain over the last few years has been done and summarized in Table 4. Patagankar et al. have shown that a significantly prolonged duration of postoperative analgesia was seen in the clonidine group. No significant difference in intraoperative heart rate, blood pressure and postoperative sedation score and adverse effects was seen in the study. ${ }^{17}$

Shini et al. have shown the duration of analgesia to be prolonged with the clonidine and ropivacaine $(380$ minutes vs 544 minutes in our study). None of the subjects was treated for bradycardia or hypotension or motor impairment in the subsequent 24 hours. ${ }^{18}$ Goodarzi et al. in a US-based study also showed that the addition of clonidine to ropivacaine significantly increased the analgesic duration (7.2 hrs versus 3.3 hours). They reported no cases of urinary retention ( 5 cases seen in our study) or hypertension and bradycardia. Our study had a larger sample size which was one of the reasons for the increased number of urinary retention cases being seen. Overall, clonidine addition reported no additional side effects. ${ }^{19}$ Nagappa et al. showed that mean pain scores assessed via VAS were significantly lower in the clonidine group, a finding seen in our study. They 
also did not see any clinically significant hemodynamic changes or other side effects in either of the groups. ${ }^{20}$

Gupta et al. also showed that the addition of dexmedetomidine or clonidine to caudal ropivacaine significantly promoted analgesic time (which was like our study). No significant difference was observed in the incidence of hemodynamic changes or side effects. A similar side effect profile has been seen in our study. ${ }^{21}$ Manickam et al. compared 3 groups - Group A: $1 \mathrm{ml} / \mathrm{kg}$ of $0.1 \%$ ropivacaine, group B: $1 \mathrm{ml} / \mathrm{kg}$ of $0.1 \%$ ropivacaine with clonidine $1 \mathrm{mcg} / \mathrm{kg}$, and Group C: $1 \mathrm{ml} / \mathrm{kg}$ of $0.2 \%$ ropivacaine. It was seen that the mean duration of analgesia was $243.7 \pm 99.29 \mathrm{~min}$ in the ropivacaine alone group while it was $590.25 \pm 83.93 \mathrm{~min}$ ropivacaine and clonidine group. The duration was 544.83 minutes in our study. They also concluded that clonidine $1 \mathrm{mcg} / \mathrm{kg}$ with ropivacaine $0.1 \%$ prolonged the duration and quality of analgesia compared to plain ropivacaine $0.1 \%{ }^{10}$ Laha et al. showed that clonidine along with ropivacaine in caudal blocks was associated with analgesia for a longer duration (975 \pm 40.5 minutes) in comparison to the ropivacaine only group (466 \pm 0.94 minutes). But they showed no significant difference in terms of the hemodynamic parameters. ${ }^{9}$ Bajwah et al. have also shown that the duration of analgesia was prolonged with the addition of clonidine to ropivacaine for caudal blocks. There was no difference in terms of complications. They concluded that the quality of analgesia improved intraoperatively and was achieved for a longer time postoperatively.12 Archana et al. showed that the duration of analgesia was 270 mins in those given $0.25 \%$ bupivacaine $0.75 \mathrm{ml} / \mathrm{kg}$ and $615 \mathrm{mins}$ in those given clonidine $2 \mu \mathrm{g} / \mathrm{kg}$ as an adjuvant. In this study, the longer duration of analgesia maybe because the pain was assessed by parents, where there was some inconsistency in determining the duration of analgesia. ${ }^{22}$

\section{CONCLUSIONS}

The study showed that the addition of clonidine to ropivacaine for caudal blocks in children was associated with better quality of pain control and a longer duration of analgesia without any additional motor blockade. There was no significant difference seen in terms of complications like hypotension and bradycardia. The group that received Ropivacaine with Clonidine as an adjunct was associated with statistically lower SBP, DBP and mean heart rate, however, these were not clinically significant, and did not require treatment.

Data sharing statement provided by the authors is available with the full text of this article at jemds.com.

Financial or other competing interests: None.

Disclosure forms provided by the authors are available with the full text of this article at jemds.com.

\section{REFERENCES}

[1] Campbell MF. Caudal anesthesia in children. J Urol 1933;30:245-9.

[2] Wolf AR, Hughes D, Wade A, et al. Postoperative analgesia after pediatric orchidopexy: evaluation of a bupivacaine-morphine mixture. $\mathrm{Br} J$ Anaesth 1990;64(4):430-5.

[3] Habre W, Bergesio R, Johnson C, et al. Pharmacokinetics of ropivacaine following caudal analgesia in children. Paediatr Anaesth 2000;10(2):143-7.

[4] Yildiz TS, Korkmaz F, Solak M, et al. Clonidine addition prolongs the duration of caudal analgesia. Acta Anaesthesiol Scand 2006;50(4):501-4.

[5] Tripi PA, Palmer JS, Thomas S, Elder JS. Clonidine increases duration of bupivacaine caudal analgesia for ureteroneocystostomy: a double-blind prospective trial. J Urol 2005;174:1081-3.

[6] Joshi W, Connelly NR, Freeman K, et al. Analgesic effect of clonidine added to bupivacaine $0.125 \%$ in paediatric caudal blockade. Paediatr Anaesth 2004;14(6):483-6.

[7] Hansen TG, Ilett KF, Lim SI, et al. Pharmacokinetics and clinical efficacy of long-term postoperative epidural ropivacaine infusion in children. $\mathrm{Br} \mathrm{J}$ Anaesth 2000;85(3):347-53.

[8] Koinig H, Krenn CG, Glaser C, et al. The dose-response of caudal ropivacaine in children. Anesthesiology 1999;90(5):1339-44.

[9] Laha A, Ghosh S, Das H. Comparison of caudal analgesia between ropivacaine and ropivacaine with clonidine in children: A randomized controlled trial. Saudi J Anaesth 2012;6(3):197-200.

[10] Manickam A, Vakamudi M, Parameswari A, et al. Efficacy of clonidine as an adjuvant to ropivacaine for caudal analgesia in children undergoing subumbilical surgery. J Anaesthesiol Clin Pharmacol 2012;28(2):185-9.

[11] Kuthiala G, Ghaudary G. Ropivacaine: a review of its pharmacology and clinical use. Indian J Anaesth 2011;55(2):104-10.

[12] Bajwa SJS, Kaur J, Bajwa SK, et al. Caudal ropivacaineclonidine: a better post-operative analgesia approach. Indian J Anaesth 2010;54(3):226-30.

[13] Singelyn FJ, Gouverneur JM, Robert A. A minimum dose of clonidine added to mepivacaine prolongs the duration of anesthesia and analgesia after brachial plexus block. Anaesth Analg 1996;83(5):1046-50.

[14] El Saied AH, Steyn MP, Ansermino JM. Clonidine prolongs the effect of ropivacaine for axillary brachial plexus blockade. Can J Anaesth 2000;47(10):962-7.

[15] Ivani G, DeNegri P, Conio A, et al. Comparison of racemic bupivacaine, ropivacaine, and levo-bupivacaine for pediatric caudal anesthesia: effects on postoperative analgesia and motor block. Reg Anesth Pain Med 2002;27(2):157-61.

[16] Ivani G, Mereto N, Lampugnani E, et al. Ropivacaine in paediatric surgery: preliminary results. Paediatr Anaesth 1998;8(2):127-9.

[17] Patangankar JV, Dhumal P. Adjuvent clonidine with ropivacaine in caudal block improves postoperative analgesia in paediatric patients. International Journal of Innovative Science and Research Technology 2021;6(1):1054-59.

[18] Shini AS, Suja KC, Linette MJ. Comparison of the efficacy of ropivacaine-clonidine mixture with plain ropivacaine for caudal analagesia in paediatric lower abdominal surgeries. J Evid Based Med Healthc 2020;7(30):145963. 
[19] Goodarzi M, Scott G, Matar M, et al. Comparison of ropivacaine-clonidine with plain ropivacaine for caudal analgesia in children. American society of anesthesiologists. 2000;93(3 Suppl 2):A1310.

[20] Nagappa S, Kalappa S, Sridhara RB. Clonidine as an adjuvant to caudal epidural ropivacaine for lumbosacral spine surgeries. Anesth Essays Res 2018;12(1):240-5.
[21] Gupta S, Pratap V. Addition of clonidine or dexmedetomidine to ropivacaine prolongs caudal analgesia in children. Indian J Pain 2014;28(1):36-41.

[22] Koul A, Pant D, Sood J. Caudal clonidine in a day care pediatric surgery. Indian J Anaesth 2009;53(4):450-4. 